\title{
Pengaruh Implementasi Sistem Informasi Keuangan Daerah Terhadap Kualitas Pelayanan Internal : Peran Kecerdasan Emosional Sebagai Intervening Variable
}

\author{
Jamali $^{1}$, Nurwahidah ${ }^{2}$ \\ 1,2 Akademi Keuangan Perbankan Nusantara, Aceh Timur, \\ Indonesia
}

\begin{abstract}
Abstrak. Penelitian ini menginvestigasi pengaruh implementasi sistem informasi keuangan daerah (SIKD) terhadap kualitas pelayanan internal menggunakan kecerdasan emosional sebagai variabel intervening. Penelitian dilakukan satuan kerja pemerintah daerah (SKPD) di jajaran pemerintah kota Banda Aceh. Pengumpulan data melalui penyebaran kuesioner kepada 170 orang pegawai yang diambil secara proporsional sampling menurut SKPD. Menggunakan structural equation modeling sebagai model analisis data, penelitian menemukan bahwa implementasi SIKD berpengaruh positif dan signifikan terbadap kecerdasan emosional pegawai dan kualitas pelayanan internal. Keberadaan kecerdasan emosional tidak hanya berpengaruh signifikan terhadap peningkatan kualitas pelayanan internal, tetapi juga memediasi pengaruh implementasi SIKD terhadap kualitas pelayanan internal SKPD.
\end{abstract}

Kata kunci: Kualitas pelayanan internal, kecerdasan emosional, implementasi SIKD, Structural equation modeling.

\begin{abstract}
This study investigates the effect of implementing a regional financial information system (SIKD) on the quality of internal services using emotional intelligence as an intervening variable. The research was conducted by the local government work unit (SKPD) in the Banda Aceh government. Data was collected through distributing questionnaires to 170 employees who were taken by proportional sampling according to SKPD. Using structural equation modeling as a data analysis model, the study found that the implementation of SIKD had a positive and significant effect on employee emotional intelligence and internal service quality. The existence of emotional intelligence not only has a significant effect on improving the quality of internal services, but also mediates the effect of implementing SIKD on the internal services quality of SKPD.
\end{abstract}

Keywords: internal services quality, employee's emotional intelligence, implementation of SIKD, Structural equation modeling.

Copyright @ 2020. Published by Lembaga Otonom Lembaga Informasi dan Riset Indonesia (KITA INFO dan RISET). 


\section{Pendahuluan}

Kualitas pelayanan internal satuan kerja pemerintah daerah (SKPD) di jajaran pemerintah kota Banda Aceh perlu mendapatkan perhatian serius. Sebagai institusi publik, SKPD tidak hanya diharapkan mampu meningkatkan kualitas pelayanan publik guna memenuhi kebutuhan masyarakat, tetapi juga mampu mendorong pelayanan yang baik dalam lingkungan internalnya. Dalam kontek ini pegawai dianggap sebagai "pelanggan internal" yang juga memerlukan layanan dalam mendukung kelancaran tugas yang mereka lakukan. Pelayanan internal dapat diartikan sebagai pelayanan antara sesama pegawai dalam lingkungan internal organisasi, baik antara pegawai dalam bidang pekerjaan yang sama maupun pegawai lintas bidang pekerjaan. Pelayanan internal menuntut adanya kerja sama yang baik antar sesama pegawai (Hallowell et al., 2016).

Secara teoritis dan didasarkan pada sejumlah penelitian sebelumnya, terdapat sejumlah faktor yang dapat mempengaruhi kualitas pelayanan internal suatu organisasi di antaranya kecerdasan emosional dalam diri pegawai dan ketersediaan sistem informasi dalam mendukung kegiatan operasional organisasi itu sendiri. Ketika pegawai yang bekerja dalam suatu organisasi adalah mereka yang memiliki kecerdasan emosional relatif baik, maka kondisi tersebut tidak hanya berdampak pada munculnya perilaku positif dalam bekerja, tetapi juga meningkatkan kemampuan kerjasama antara sesama pegawai, sehingga dalam melaksanakan pekerjaan mereka saling melayani satu sama lain.

Ketersediaan sistem informasi sangat penting artinya bagi setiap organisasi (Ahmad \& Wali, 2019). Selain dapat mendukung kelancaran pelaksanaan tugas pegawai, sistem informasi juga dapat berdampak pada kualitas pelayanan internal. Sistem informasi keuangan daerah (SIKD) misalnya, merupakan instrumen penting bagi setiap instansi pemerintah dan sangat berguna bagi pegawai dalam mendukung kelancaran tugas mereka. Semakin baik SIKD, semakin mudah bagi pegawai dalam melaksanakan tugas mereka terutama yang berkaitan dengan keuangan dalam instansi pemerintah. Apalagi penggunaan SIKD merupakan salah satu indikasi penerapan $e$ government dalam keuangan daerah. Ketika sistem informasi baik, maka implementasi e-government juga baik sehingga dapat meningkatkan kemampuan pegawai dalam bekerja (Kurniasih et al., 2013). Hal ini juga didukung oleh temuan penelitian Karniawati \& Rahmadani (2013) bahwa penerapan e-government seperti halnya dalam sistem informasi keuangan dapat meningkatkan kinerja pelayanan publik.

Hasil survei awal mengindikasikan bahwa kualitas pelayanan internal pada SKPD di kota Banda Aceh dipersepsikan berbeda oleh pegawainya. Di satu sisi ada pegawai yang memiliki persepsi relatif baik terhadap kualitas pelayanan internal pada instansi tempat mereka bekerja, dan sisi lain juga ada diantara pegawai dengan persepsi kurang baik. Demikian pula halnya dengan kecerdasan emosional, hasil survei awal mengindikasikan adanya perbedaan kecerdasan emosional di antara sesama pegawai. Selain itu, implementasi SIKD yang diterapkan oleh instansi tempat mereka bekerja juga dipersepsikan berbeda. Bila implementasi SIKD diharapkan mampu meningkatkan kualitas pelayanan instansi pemerintah, maka muncul pertanyaan empiris mengenai sejauhmana implementasi SIKD pada instansi tersebut dapat meningkatkan kualitas pelayanan internal instansi tersebut. Karena itu, penelitian ini menganalisis kualitas pelayanan internal pada SKPD dilingkungan Pemerintah Kota Banda Aceh dengan menggunakan dua variabel tersebut sebagai predictor variable. Dalam hal ini, kecerdasan emosional ditempatkan sebagai intervening variabel antara kualitas pelayanan internal di satu sisi dengan implementasi SIKD di sisi lain.

\section{Literature Review}

\section{Kualitas Pelayanan Internal}

Pegawai yang bekerja dalam suatu organisasi berpengaruh terhadap kualitas pelayanan dalam lingkungan organisasi tersebut yang kemudian mendorong beberapa perubahan vital dalam organisasi (Papasolomou-Doukakis, 2012). Dalam kontek ini, pegawai dianggap sebagai "pelanggan internal" yang juga memerlukan layanan dalam mendukung kelancaran tugas yang mereka lakukan. Pelanggan internal dapat 
didefinisikan sebagai setiap pegawai yang menerima pelayanan dari pegawai lainnya baik dalam bidang pekerjaan yang sama maupun bidang pekerjaan atau departemen yang berbeda dalam suatu organisasi dalam rangka meningkatkan kemampuan dalam menyelesaikan tugas (Hallowell et al., 2016).

Sejumlah peneliti menggunakan delapan dimensi untuk mengukur Internal Service Quality (ISQ) terdiri dari ketersediaan peralatan kerja, komunikasi, penyelarasan tujuan, pelatihan, rewards dan pengakuan, tim kerja, manajemen dan kebijakan dan prosedur (Hallowell et al., 2016). Ukuran lainnya dari kualitas pelayanan internal adalah sikap dan perilaku pegawai dalam bekerja (Wali, 2015). Sejumlah peneliti seperti Sahney et al. (2014), dan Owlia \& Aspinwall (2016) menggunakan sikap dan perilaku pegawai dalam sebagai salah satu indikator pengukuran kualitas pelayanan internal. Mereka memiliki anggapan bahwa perilaku pegawai dalam bekerja merefleksikan kualitas pelayanan internal di antara sesama mereka.

\section{Keterkaitan antara Implementasi Sistem Informasi Keuangan Daerah dan Kecerdasan Emosional Pegawai}

Penerapan sistem informasi keuangan dalam suatu instansi pemerintah dapat menciptakan suatu hasil kerja yang efisien, partisipatif, berkeadilan, demokratis, transparan dan bertanggung jawab bila ditunjang dengan sistem aparatur negara yang modern, yang dilandasi oleh derajat rasionalitas yang tinggi. Penerapan sistem informasi sepertihalnya SIKD misalnya, dapat mendorong pegawai untuk bekerja lebih baik sehingga mampu memecahkan masalah yang berkaitan dengan pekerjaannya serta selalu bersemangat dalam bekerja. Kemampuan memecahkan masalah serta kecenderungan untuk selalu bersemangat dalam bekerja dapat dijadikan refleksi dari kecerdasan emosional seseorang pegawai. Sebagaimana dikemukakan oleh Eysenck (2011: 32) bahwa pegawai yang memiliki EQ tinggi lebih cerdas secara emosional sehingga kemampuannya dalam memecahkan masalah yang berkaitan dengan pekerjaannya akan lebih baik. Berbagai temuan penelitian membuktikan adanya pengaruh sistem informasi terhadap kecerdasan emosional dankinerja pegawai instansi pemerintah. Sepertihalnya penelitian Sudaryanti (2013) dan Osodo \& Jemaiyo (2015) membuktikan bahwa sistem informasi keuangan sepertihalnya SIKD berpengaruh positif dan signifikan terhadap kecerdasan emosional dan kinerja pegawai instansi pemerintah.

\section{Keterkaitan antara Kecerdasan Emosional dan Kualitas Pelayanan Internal}

Kecerdasan emosional dalam diri pegawai yang bekerja pada suatu organisasi dapat berdampak pada kualitas pelayanan internal dalam organisasi tersebut (Rizal et al., 2015). Pegawai dengan kecerdasan emosional relatif baik akan mengenali perasaan orang lain dalam lingkungan kerjanya dan mampu mengelola emosi secara baik. Kondisi ini dapat berdampak positif pada hubungan antara sama pegawai dan sinergisitas mereka dalam bekerja (Nggermanto, 2012:98). Ketika pegawai yang bekerja dalam suatu organisasi adalah mereka yang memiliki kecerdasan emosional relatif baik, maka kondisi tersebut tidak hanya berdampak pada munculnya perilaku positif dalam bekerja, tetapi juga meningkatkan kemampuan kerjasama antara sesama pegawai, sehingga dalam melaksanakan pekerjaan mereka saling melayani satu sama lain.

\section{Keterkaitan antara Implementasi Sistem Informasi Keuangan Daerah dan Pelayanan Internal}

Ketersediaan sistem informasi yang mendukung kelancaran pelaksanaan tugas pegawai juga dapat berdampak pada kualitas pelayanan internal. Sistem informasi keuangan daerah misalnya, merupakan instrumen penting bagi setiap instansi pemerintah dan sangat berguna bagi pegawai dalam mendukung kelancaran tugas mereka. Semakin baik sistem informasi keuangan daerah, semakin mudah bagi pegawai dalam melaksanakan tugas mereka terutama yang berkaitan dengan keuangan dalam instansi pemerintah. Apalagi penggunaan sistem informasi keuangan daerah merupakan salah satu indikasi penerapan e-government dalam keuangan daerah. Ketika sistem informasi baik, maka implementasi e-government juga baik sehingga dapat meningkatkan kemampuan pegawai dalam bekerja (Kurniasih et al., 2013). Hal ini juga didukung oleh temuan penelitian Karniawati \& Rahmadani (2013) bahwa penerapan e-government 
seperti halnya dalam sistem informasi keuangan dapat meningkatkan kinerja pelayanan publik.

Adanya keterkaitan antara sistem informasi sebagai wujud dari implementasie-government dengan kualitas pelayanan secara eksplisit dinyatakan oleh Elysia et al. (2017) bahwa implementasi e-government dapat meningkatkan transparansi dalam proses pengambilan keputusan dengan penyediaan informasi serta pelacakan dalam jaringan (on-line tracking) yang mudah diakses oleh setiap anggota masyarakat termasuk pegawai instansi pemerintah. Hal ini berarti bahwa sistem informasi dapat mendukung peningkatan kualitas pelayanan internal pada setiap organisasi.

\section{Metodologi Penelitian}

Penelitian ini dilakukan pada 17 SKPD dijajaran Pemerintah Kota Banda Aceh. Objek penelitian berhubungan dengan keterkaitan antara kualitas pelayanan internal, kecerdasan emosional pegawai dan sistem informasi keuangan daerah (SIKD). Dalam hal ini, kecerdasan emosional pegawai dijadikan variabel intervening antara implementasi SIKD dengan kualitas pelayanan internal. Populasi penelitian adalah seluruh pegawai pada 17 SKPD yang dijadikan unit analisis. Sampel pada setiap SKPD diambil 10 orang pegawai. Dengan demikian jumlah sampel secara keseluruhan sebanyak 170 orang

\section{Variabel yang dioperasionalkan dalam} penelitian ini terdiri dari kualitas pelayanan internal, kecerdasan emosional pegawai dan implementasi SIKD. Pengukuran kualitas pelayanan internal diadopsi dari pendapat Hallowell et al. (2016) menggunakan 6 indikator meliputi adanya komunikasi yang baik di antara sesama pegawai, keselarasan tujuan pegawai dalam bekerja, timkerja yang solid dan saling membantu, kesopanan pegawai, perilaku pegawai dalam bekerja dan sikap menghargai di antara sesama pegawai. Pengukuran implementasi SIKD mengacu pada penelitian Manaroinsang (2014) menggunakan 6 indikator meliputi implementasi SIKD mendukung desentralisasi pengambilan keputusan, keterlibatan pimpinan dalam mendesain SIKD, SIKD dapat menyahuti tuntutan masyarakat tentang transparansi dan akuntabilitas pengelolaan keuangan daerah, implementasi
SIKD dapat memenuhi harapan pengelolaan keuangan daerah, kemampuan adaptasi pegawai dalam mengimplementasikan SIKD dan Proses implementasi SIKD dapat diterima oleh seluruh pegawai. Selanjutnya pengukuran kecerdasan emosional mengacu pada pendapat Goleman (2015) menggunakan 5 indikator meliputi kesadaran diri (self-awareness), pengaturan diri (selfregulation), kemampuan sosial, empati, dan penuh semangat.

Pengumpulan data dilakukan dengan cara mengedarkan kuesioner kepada para pegawai. Kuesioner tersebut pernyataan/pernyataan berkaitan dengan indikator-indikator kualitas pelayanan internal, implementasi SIKD dan kecerdasan emosional. Mengingat ketiga data tersebut merupakan data kualitatif diperlukan adanya proses kuantifikasi data agar dapat diolah dan dianalisis secara statistik. Cara yang dilakukan adalah menyediakan alternatif pilihan tingkat kesetujuan untuk setiap pernyataan (Farnita \& Amri, 2013; Iskandar \& Amri, 2014; Amri, 2015). Masing-masing pernyataan disediakan alternatif pilihan jawaban dalam bentuk tingkat kesetujuan. Pegawai diminta untuk memberikan check list $(\sqrt{ })$ pada alternatif pilihan jawaban yang mereka anggap paling tepat. Skala pengukuran yang digunakan dalam penelitian ini adalah skala interval dalam bentuk skala Likert dengan skor 1, 2, 3, 4 dan 5. Penggunaan skala tersebut untuk mengkuantatifkan data kualitatif telah umum dilakukan oleh para peneliti (Amri \& Taharuddin, 2011; Amri, 2012; Ratnawati \& Amri, 2013; Amri, 2014).

Selanjutnya model analisis yang digunakan untuk menganalisis hubungan kausalitas antar variabel dalah statistik multivariate structural equation model (SEM). Peralatan statistik ini memiliki kelebihan dibandingkan dengan model analisis statistik lainnya karena tidak hana dapat menguji hubungan antar sesama variabel, tetapi juga hubungan antara variabel dengan indikator dalam waktu bersamaan (Ghozali, 2016).

\section{Hasil dan Pembahasan}

Penggunaan SEM sebagai alat analisis data dilakukan melalui beberapa rangkaian pengujian statistik. Langkah pertama melakukan uji 
signifikansi bobot faktor bagi sejumlah indikator yang digunakan untuk mengukur variabel yang teliti. Uji ini sering juga disebut dengan confirmatory factor analysis (CFA) yang dimaksudkan untuk mengukur sejauhmana suatu indikator dalam variabel tertentu dinyatakan valid untuk mengukur variabel yang bersangkutan. Ukuran yang sering digunakan adalah nilai loading factor yang dihasilkan melalui perhitungan statistik dengan ketentuan bahwa nilai yang dapat diterima minimal 0,70 (Ghozali, 2011). Ukuran lainnya adalah nilai critical ratio ( $>$ $2,00)$ dan nilai $p$-value $(<0,05)$. Ketika suatu indikator memiliki nilai loading factor $<0,70$ atau critical ratio $<2,00$ dan p-value $>0,50$, maka indikator tersebut dianggap tidak valid dan tidak mampu merefleksikan variabel yang diteliti, sehingga harus direduksi dari sistem persamaan SEM.

Dalam penelitian ini, variabel penelitian terdiri dari kualitas pelayanan internal, kecerdasan emosional dan implementasi SIKD. Hasil CFA dengan menggunakan software AMOS 21 memperlihatkan nilai loading factor, critical ratio dan $p$-value masing-masing indikator pada setiap variabel penelitian seperti ditunjukkan dalam Tabel 1. berkaitan dengan pelayanan internal (KPI1) dan indikator keempat berkaitan dengan implementasi SIKD (SI4). Kedua indikator tersebut kemudian direduksi dari sistem persamaan dan kemudian uji CFA dilanjutkan pada tahap kedua. Pada tahap ini masih terdapat satu indikator yang tidak memenuhi syarat yakni indikator kelima pada variabel SIKD (SI5). Setelah indikator tersebut direduksi, kemudian uji CFA dilanjutkan hingga tahap ketiga. Pada tahap ketiga, seluruh indikator telah memenuhi kriteria yang ditentukan. Dengan kata lain, semua indikator telah memiliki nilai loading factor $>0,70$, nilai critical ratio $>2,00$ dan $p$-value $<0,05$.

Langkah kedua adalah melakukan uji kesesuaian model (measurement model). Uji ini sering juga dikenal dengan goodness of fit test (kebaikan model). Uji ini menggunakan sejumlah nilai statistik yakni $\mathrm{X}^{2}$ atau chi-square statistik, GFI (Goodness of Fit Index), AGFI (Adjusted Goodness of Fit Index), CFI (Comparative Fit Index), TLI (Tucker Lewis Index) dan Root Mean Square Error of Approximation (RMSEA). Ketentuan statistik untuk masingmasing nilai tersebut sebagai dasar penentuan suatu model dikatakan goodness of fit adalah: $\mathrm{X}^{2}$ hit $>X^{2}$ tabel, $p$-value $>0,05$, GFI $>0,90$, AGFI $>0,90$, CFI $>0,95$, TLI $>0,95$ dan RMSEA $<$

Tabel 1. Hasil Confirmatory Factor Analysis

\begin{tabular}{|c|c|c|c|c|c|c|c|c|c|c|c|}
\hline & & & \multicolumn{3}{|c|}{ Tabas 1} & \multicolumn{3}{|c|}{ Tabas 2} & \multicolumn{3}{|c|}{ Tabap 3} \\
\hline & & & $\begin{array}{l}\text { Loading } \\
\text { Factor }\end{array}$ & $\begin{array}{l}\text { Critical } \\
\text { Ratio }\end{array}$ & P-Value & $\begin{array}{l}\text { Loading } \\
\text { Factor }\end{array}$ & $\begin{array}{c}\text { Critical } \\
\text { Ratio }\end{array}$ & \begin{tabular}{c|}
$P-$ \\
Value
\end{tabular} & $\begin{array}{l}\text { Loading } \\
\text { Factor }\end{array}$ & $\begin{array}{l}\text { Critical } \\
\text { Ratio }\end{array}$ & P-Value \\
\hline KPI1 & $<--$ & Pelayanan_Internal & ,576 & & & & & & & & \\
\hline KPI2 & $<\ldots$ & Pelayanan_Internal & 807 & 7,651 & **** &, 799 & & & ,799 & & \\
\hline KPI3 & $<-$ & Pelayanan_Internal & .716 & 7,113 & $* * *$ & .724 & 9,908 & $* * *$ & .725 & 9,908 & $* * *$ \\
\hline KPI4 & $<-$ & Pelayanan_Internal & .786 & 7,534 & $* * *$ & .787 & 10,963 & $* * *$ & .787 & 10,964 & $* * * *$ \\
\hline KPI5 & $<\ldots$ & Pelayanan_Internal & 811 & 7,673 & $* * *$ &, 812 & 11,401 & $* * * \infty$ &, 812 & 11,399 & *⿻一; * \\
\hline KPI6 & $<-$ & Pelayanan_Internal & 827 & 7,756 & $* * *$ & 827 & 11,643 & $* * *$ & .827 & 11,645 & ***; \\
\hline SI5 & $<-$ & Implementasi_SIKD & .716 & & & ,683 & & & & & \\
\hline SI4 & $<--$ & Implementasi_SIKD & 699 & 8,675 & $* * *$ & & & & & & \\
\hline SI 3 & $<-$ & Implementasi_SIKD & 877 & 10,802 & $* * *$ & 913 & 10,355 & $* * *$ &, 948 & 14,094 & $* * *$ \\
\hline SI 2 & $<-$ & Implementasi_SIKD & .776 & 9,625 & $* * *$ & .739 & 8,749 & $* * *$ & .739 & 10,644 & 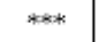 \\
\hline SI1 & $<-$ & Implementasi_SIKD & .769 & 9,542 & $* * *$ & .750 & 8,859 & $* * *$ & .741 & 10,675 & ***; \\
\hline SI6 & $<\ldots$ & Implementasi_SIKD &, 741 & 9,197 & $* * *$ &, 781 & 9,183 & $* * * *$ & 808 & & \\
\hline KE1 & $<-$ & Kecerdasan_Emosional & .778 & & & .779 & & & .779 & & \\
\hline KE2 & $<-$ & Kecerdasan_Emosional &, 770 & 10,202 & $* * *$ & .769 & 10,185 & $* * *$ & .769 & 10,165 & $* * * *$ \\
\hline KE3 & $<-$ & Kecerdasan_Emosional & .750 & 9,893 & $* * *$ &, 751 & 9,920 & $* * *$ &, 752 & 9,915 & $* * *$ \\
\hline KE4 & $<-$ & Kecerdasan_Emosional & .759 & 10,038 & $* * *$ &, 756 & 9,998 & $* * *$ & .756 & 9,978 & *** \\
\hline KE5 & $<-$ & Kecerdasan_Emosional &, 775 & 10,276 & $* * *$ & .777 & 10,310 & $* * *$ &, 778 & 10,304 & ***; \\
\hline
\end{tabular}

Sumber: Data Primer (Diolah), $2020 . \quad * * *=0.001$

Seperti dalam tabel di atas, uji CFA dalam penelitian ini terdiri dari tiga tahap. Pada tahap pertama, terdapat dua indikator dengan loading factor di bawah 0,70 yakni indikator pertama
0,08. Hasil uji measurement model seperti ditunjukkan dalam Tabel 2 . 
Tabel 2. Hasil Measurement Model

\begin{tabular}{|c|c|c|c|c|}
\hline Goodness-of-Fit Index & Kriteria Nilai & Tahap 1 & Tahap 2 & Tahap 3 \\
\hline$\chi^{2}-$ Chi-square & $\mathrm{X}^{2}{ }_{\text {hit }}<\mathrm{X}^{2}$ tab & $276,256>142,138$ & $234,984>109,773$ & $89,198<95,081$ \\
\hline Prob & $\geq 0,05$ & 0,000 & 0,021 & 0,081 \\
\hline GFI & $\geq 0,90$ & 0,839 & 0,841 & 0,935 \\
\hline AGFI & $\geq 0,90$ & 0,788 & 0,781 & 0,927 \\
\hline CFI & $\geq 0,95$ & 0,902 & 0,900 & 0,967 \\
\hline TLI & $\geq 0,95$ & 0,886 & 0,879 & 0,958 \\
\hline RMSEA & $\leq 0,08$ & 0,090 & 0,87 & 0,071 \\
\hline
\end{tabular}

Sumber : Data Primer (Diolah), 2020

Berdasarkan tabel 2 di atas juga dapat dilihat bahwa uji measurement model juga dilakukan tiga tahap seperti halnya uji CFA. Pada tahap pertama, belum semua kriteria terpenuhi, dimana nilai $\mathrm{X}^{2}$ hitung menunjukkan angka sebesar 276,256 lebih besar bila dibandingkan dengan $X^{2}$ tabel $(\mathrm{df}=116)$ sebesar 142,138. Nilai p-value sebesar $0,000<0,05$ juga belum
Setelah CFA dan measurement model, langkah ketiga dalam penggunaan SEM adalah melakukan uji struktural untuk keseluruhan variabel. Indikator yang dimasukan dalam tahap ini hanyalah indikator-indikator yang dinyatakan valid dalam uji CFA sebelumnya. Hasil full structural model yang menjelaskan keterkaitan antara seluruh variabel penelitian seperti terlihat dalam Gambar 1.

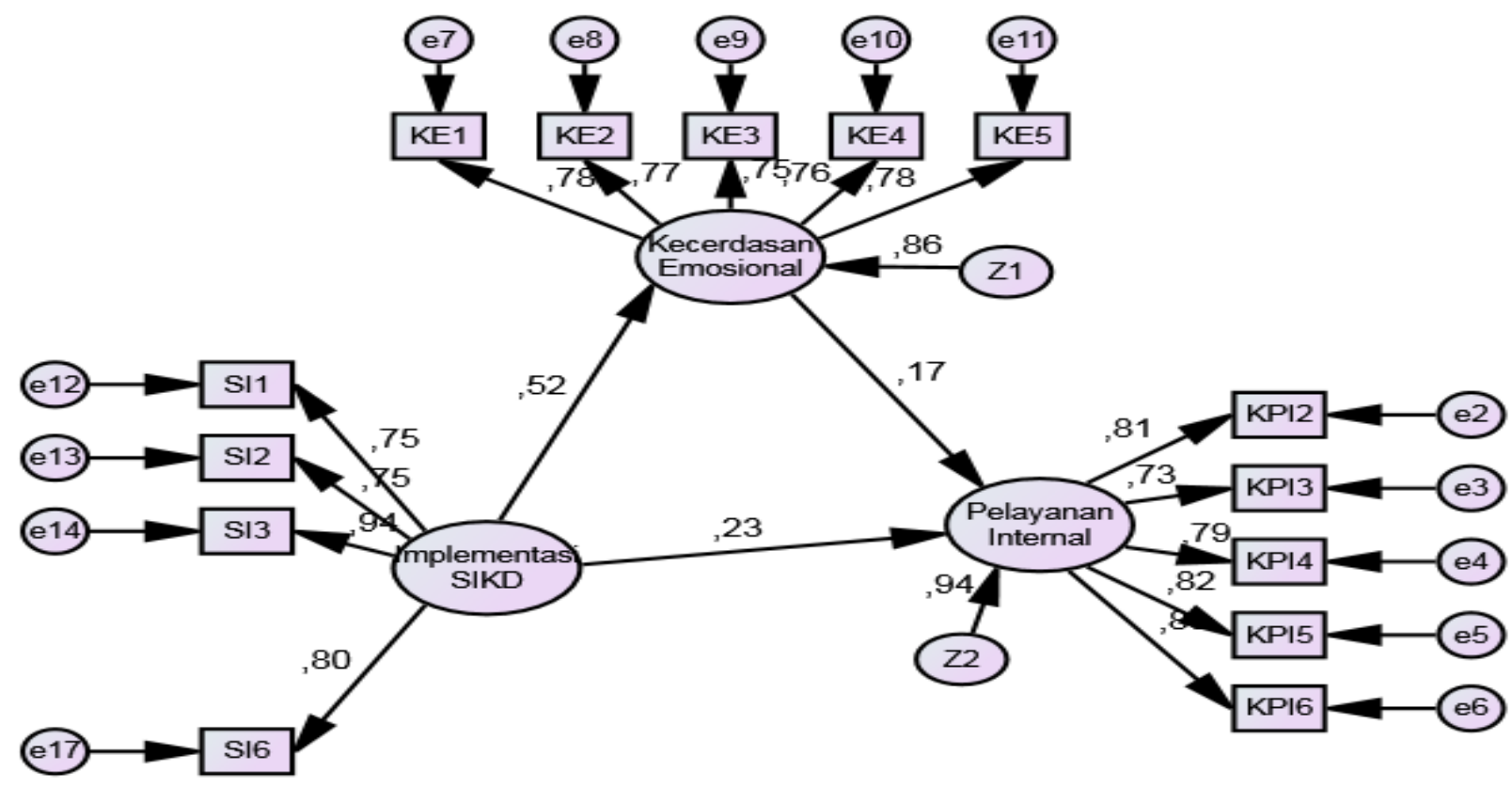

Gambar 1. Hasil Full Structural Model

memenuhi kriteria yang ditentukan. Demikian juga halnya dengan GFI, AGFI, CFI, TLI dan RMSEA juga belum memenuhi kriteria yang ditentukan sebagai syarat statistik goodness of fit. Kriteria goodness of fit terpenuhi pada uji measurement model tahap ketiga, dimana $\mathrm{X}^{2}$ hitung sebesar 89,198 lebih kecil dari $\mathrm{X}^{2}$ tabel $(\mathrm{df}=74)$ sebesar 95, 081, p-value sebesar 0,081 $(>0,05)$ dan RMSEA sebesar 0,071 $(0,08)$. Nilai GFI dan AGFI masing-masing juga lebih besar dari 0,90 , selanjutnya nilai CFI dan TLI juga lebih besar dari 0,95.
Gambar 1 di atas tidak hanya memperlihatkan nilai koefisien estimasi masing-masing variabel, tetapi juga memperlihatkan nilai loading factor masing-masing indikator dalam setiap variabel. Koefisien estimasi yang menjelaskan arah pengaruh antar variabel seperti ditunjukkan dalam Tabel 3.

Tabel 3. Koefisien Estimasi Masing-masing Variabel

\begin{tabular}{|c|c|c|c|c|c|}
\hline & & & $\begin{array}{l}\text { Koefisien } \\
\text { Estimasi }\end{array}$ & $\begin{array}{c}\text { Critical } \\
\text { ratio }\end{array}$ & $\mathrm{p}$-value \\
\hline Implementasi_SIKD & $<-\infty$ & Kecerdasan_Emosional & .516 & 5,928 & 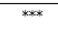 \\
\hline Implementasi_SIKD & $<-$ & Pelayanan_Internal &, 230 & 3,538 & wex \\
\hline Kecerdasan_Emosional & $<-$ & Pelayanan_Internal & 169 & 2,010 & ,044 \\
\hline
\end{tabular}


Tabel 3 di atas memperlihatkan bahwa implementasi SIKD berpengaruh positif dan signifikan terhadap kecerdasan emosional dan pelayanan internal, ditunjukkan dengan nilai koefisien estimasi masing-masing sebesar 0,516 dan 0,230 , dengan nilai $\mathrm{p}$-value masing-masing sebesar 0,001 . Hal ini mengindikasikan bahwa implementasi SIKD berdampak pada perbaikan kecerdasan emosional pegawai dan peningkatan kualitas pelayanan internal. Semakin baik implementasi sistem informasi tersebut, semakin baik pula kecerdasan emosional pegawai dan kualitas pelayanan internal pada SKPD di jajaran pemerintah kota Banda Aceh. Temuan ini mengkonfirmasi hasil kajian Sudaryanti (2013) dan Osodo \& Jemaiyo (2015) yang juga memberikan bukti empiris bahwa sistem informasi dalam suatu organisasi berpengaruh positif dan signifikan terhadap kecerdasan emosional pegawai dan kemampuan mereka untuk bekerja sama dalam melaksanakan pekerjaan yang dibebankan.
Gambar 1 di atas menginformasikan bahwa pengaruh implementasi SIKD terhadap kualitas pelayanan internal dapat terjadi melalui kecerdasan emosional pegawai sebagai 36ariable perantara (indirect effect). Selain itu, implementasi 36ariab informasi tersebut juga dapat terjadi secara langsung (direct effect) terhadap kualitas pelayanan internal. Seperti dalam tabel 3, koefisien estimasi kecerdasan emosional terhadap pelayanan internal sebesar 0,169 . Secara variable besarnya pengaruh langsung kecerdasan emosional terhadap pelayanan internal dicari dengan meng-kuadrat-kan nilai koefisien estimasi tersebut, sehingga dapat diinterpretasikan bahwa pengaruh langsung kecerdasan emosional terhadap pelayanan internal sebesar 2,86 persen. Selanjutnya nilai koefisien estimasi SIKD dan kecerdasan emosional terhadap pelayanan internal masingmasing sebesar 0,516 dan 0,230. Pengaruh langsung kedua variable tersebut terhadap kecerdasan emosional pegawai dan pelayanan internal instansi tersebut masing-masing sebesar

Tabel 4. Pengaruh langsung dan tidak langsung antar varibel

\begin{tabular}{|l|l|c|c|}
\hline \multicolumn{1}{|c|}{ Bentuk Pengaruh } & \multicolumn{1}{|c|}{ Variabel yang Dianalisis } & $\begin{array}{c}\text { Koefisien } \\
\text { Estimasi }\end{array}$ & $\begin{array}{c}\text { Besarnya } \\
\text { Pengaruh }\end{array}$ \\
\hline Pengaruh langsung \\
(direct effect) & Implementasi SIKD $(\mathrm{X})$ terhadap kecerdasan emosional $(\mathrm{Y})$ & 0,516 & $26,63 \%$ \\
& Implementasi SIKD (X) terhadap pelayanan internal $(\mathrm{Z})$ & 0,230 & $5,29 \%$ \\
& Kecerdasan emosional $(\mathrm{Y})$ terhadap pelayanan internal $(\mathrm{Z})$ & 0,169 & $2,86 \%$ \\
\hline $\begin{array}{l}\text { Pengaruh tidak langsung } \\
\text { (indirect effect) }\end{array}$ & Implementasi SIKD (X) terhadap pelayanan internal $(\mathrm{Z})$ & $(0,516 \times$ & $8,72 \%$ \\
\hline
\end{tabular}

Sumber: Data Primer (Diolah), 2020

Kecerdasan emosional juga berpengaruh positif dan signifikan terhadap kualitas pelayanan internal. Interpretasi ini secara statistik dapat dilihat dari nilai koefisien estimasi sebesar 0,169 dengan p-value sebesar 0,044 $(<0,05)$. Peningkatan kecerdasan emosional pegawai berdampak secara nyata terhadap perbaikan kualitas pelayanan internal SKPD di jajaran pemerintah kota Banda Aceh. Temuan ini mengkonfirmasi pendapat Nggermanto (2012:98) yang menyatakan bahwa pegawai dengan kecerdasan emosional yang baik akan mengenali perasaan orang lain dalam lingkungan kerjanya, mampu mengelola emosi secara baik dan kondisi tersebut berdampak positif pada dan sinergisitas mereka dalam melaksanakan tugas.
26,63 persen dan 5,29 persen. Untuk lebih jelasnya mengenai pengaruh langsung dan tidak langsung antar variable dapat dilihat Tabel 4.

Mengacu pada Tabel 4 di atas dapat diketahui pengaruh tidak langsung (indirect effect) implementasi SIKD terhadap pelayanan internal melalui kecerdasan emosional sebagai variabel perantara menunjukkan angka sebesar 22,44 persen. Angka ini jauh lebih besar dibandingkan dengan pengaruh langsung (direct effect) sebesar 4,00 persen. Hal ini berarti bahwa kecerdasan emosional memperkuat pengaruh implementasi SIKD terhadap kualitas pelayanan internal SKPD di jajaran pemerintah kota Banda Aceh. Sehingga dapat dipahami bahwa keberadaan kecerdasan emosional sebagai variabel intervening juga memediasi pengaruh implementasi SIKD terhadap kualitas pelayanan internal. 


\section{Simpulan}

Berdasarkan hasil dan pembahasan yang telah dipaparkan sebelumnya dapat disimpulkan bahwa kecerdasan emosional pegawai dan pelayanan internal pada SKPD di jajaran pemerintah kota Banda Aceh secara positif dan signifikan dipengaruhi oleh implementasi SIKD. Peningkatan SIKD secara nyata dapat meningkatkan kecerdasan emosional pegawai kualitas pelayanan internal. Selain itu, kualitas pelayanan internal juga secara positif dan signifikan dipengaruhi oleh kecerdasan emosional pegawai. Keberadaan kecerdasan emosional tidak hanya memperkuat pengaruh implementasi SIKD terhadap kualitas pelayanan internal, tetapi juga secara nyata memediasi hubungan kausalitas antara kedua variabel tersebut.

Penelitian ini berimplikasi bahwa upaya peningkatan kualitas pelayanan internal pada SKPD di jajaran pemerintah kota Banda Aceh dapat dilakukan melalui upaya peningkatan kualitas SIKD dan kecerdasan emosional pegawai. Karena itu, para pimpinan SKPD perlu melakukan intervensi kebijakan yang berorientasi pada peningkatan SIKD dan kecerdasan emosional para pegawainya.

\section{Ucapan Terima Kasih}

Penulis menyampaikan terima kasih yang sebesar-besarnya kepada Deputi Bidang Penguatan Riset dan Pengembangan Kementerian Riset dan Teknologi/Badan Riset dan Inovasi Nasional sebagai penyandang dana penelitian pada skema Penelitian Dosen Pemula (PDP) Tahun 2020. Rasa terima kasih juga penulis haturkan kepada LPPM AKUBANKNusantara yang telah menfasilitasi para dosen dalam memperoleh dana hibah penelitian.

\section{Daftar Pustaka}

Ahmad, L., \& Wali, M. (2019). Perancangan software asisten dosen sebagai media dalam pelaksanaan computer assisted learning di AMIK Indonesia Banda Aceh. Smart Comp: Jurnalnya Orang Pintar Komputer, 8 (1), 38-43.
Amri, K. (2012). Faktor-faktor yang mempengaruhi kepercayaan pengguna layanan perawatan kecantikan, Jurnal Manajemen dan Keuangan, 1(1), 10-21.

Amri, K. (2014). Pengaruh kemampuan kerja, komunikasi, kekompakkan tim kerja dan kepemimpinan terhadap kualitas laporan hasil pemeriksaan Inspektorat Aceh. Jurnal Ilmiah Manajemen Muhammadiyah, 2(2).

Amri, K. (2015). Pengaruh perilaku kepemimpinan dan motivasi dalam meningkatkan produktivitas kerja karyawan PT Bank Sinarmas Tbk cabang Banda Aceh, Jurnal Ekonomi Manajemen dan Bisnis, 3(1), 522-536.

Amri, K., \& Taharuddin. (2011). Sensitivitas respon konsumen terhadap merek, Jurnal Samudra Ekonomi dan Bisnis, 2(2), 114137.

Elysia, V., Wihadanto, A., \& Sumartono. (2017). Implementasi e-government untuk mendorong publik yang terintegrasi di Indonesia, Proceeding Optimalisasi Peran Sains dan Teknologi untuk Mewujudkan Smart City.

Eysenck, M. W. (2011). Fundamental of Cognition, Taylor \& Francis Group, New York.

Farnita, I., \& Amri, K. (2013). Persepsi mahasiswa terhadap kualitas layanan Pendidikan Akademi Manajemen Informatika dan Komputer Indonesia (AMIKI) Banda Aceh. Jurnal Ekonomi Manajemen dan Bisnis 1 (1), 118-139

Ghozali, I. (2016). Structural Equation Modelling, Metode Alternatif Dengan Partial Least Square PLS, Badan Penerbit Universitas Diponegoro, Semarang.

Goleman, D. (2015). Emotional Intelligence, Penerjemah T. Hermaya, PT Gramedia Pustaka Utama, Jakarta. 
Hallowell, R., Schlesinger, L. A., \&Zornitsky, J. (2016). Internal service quality, customer and job satisfaction: Linkages and implications for management. Human Resource Planning, 19, 20-31.

Iskandar, D., \& Amri, K. (2014). Pengaruh daya Tarik iklan, kualitas pesan iklan dan frekuensi penayangan iklan terhadap efektivitas iklan televisi produk mie instan merek Indomie Goreng Cabe Ijo, Jurnal Ekonomi Manajemen dan Bisnis, 2(1), 424-437.

Karniawati, N., \& Rahmadani, R. (2013) Analisis kebijakan penerapan egovernment melalui sistem informasi manajemen kepegawaian (Simpeg) (Suatu Studi Pada Biro Kepegawaian Sekretariat Daerah Provinsi Jawa Barat), Majalah Ilmiah UNIKOM, 7(2): 212-215.

Kurniasih, D., Tatik, F., \& Sukaesih, P. (2013) Pengaruh implementasi kebijakan egovernment terhadap kinerja aparatur kota Cimahi, Sosiohumaniora, 15(1): 6-9.

Manaroinsang, J. (2014). Pengaruh sistem informasi keuangan, partisipasi anggaran serta sikap perilaku aparat terhadap kinerja keuangan daerah di provinsi Sulawesi Utara, Jurnal Aplikasi Manajemen, 12(3), 373-384.

Nggermanto, A. (2012) Quantum Quotient, Nuansa, Bandung.

Osodo, O. P., \& Jemaiyo, B. (2015). Relationship between the use of management information systems and employee job performance: Evidence From Ken India Assurance Company Limited, British Journal of Marketing Studies, 3(5), 61-70.
Owlia, M.S, \& Aspinwall, E. (2016). Quality in higher education: A survey, Total Quality Management, 7(2), 112-134.

Papasolomou-Doukakis, I. (2012). The role of employee development in customer relations: the Case of UK retail banks. Corporate Communications: An International Journal, 7(1), 62-76.

Ratnawati \& Amri, K. (2013). Pengaruh keadilan organisasional, kepercayaan pada atasan terhadap perilaku kewargaan organisasi (organizational citizenship behavior). Jurnal Ekonomi Manajemen dan Bisnis, 1(1), 56-73.

Rizal, S., Sarboini, Wali, M., \& Masitah. (2015). The effect of leadership style, compensation and organizational commitment to working satisfaction of Aceh social service employees. Journal of Applied Economic Sciences, 14 (3(65)), 797-803

Sahney, S., D. K. Banwe., \& Karunes, S. (2014) Conceptualizing Total Quality Management in High Education, The TQM Magazine, 16(2), 145-159.

Sudaryanti, D. (2013). Pengaruh penganggaran terhadap kinerja aparat pemda melalui sistem informasi keuangan daerah (Studi Kasus: Pemda Kab Kudus), Jurnal Ekonomi dan Bisnis, 12(1), 11-24.

Wali, M. (2015). Kualitas pelayanan medis dan kepuasan pasien rawat inap (Studi Kasus di Rumah Sakit Harapan Bunda Banda Aceh). Jurnal Ekonomi Manajemen dan Bisnis, 3 (1), 554-567. 